Türk Coğrafya Dergisi
Sayı 64: 51-60, istanbul
http://www.tcd.org.tr

Hakemli Makale
Reviwed Article

\title{
Karmaşık kent sistemi, kentsel büyüme kavramlarının anlaşılması ve kent modelleme teknikleri
}

\author{
Complex urban system, understanding urban growth concepts, and urban modeling \\ techniques
}

Olgu AYDINa

a) Ankara Üniversitesi, Dil ve Tarih Coğrafya Fakültesi, Coğrafya Bölümü.

Geliş/Received: 28.02.2015 Kabul /Accepted: 30.04.2015

Sorumlu yazar/Corresponding author (O. AYDIN) oaydin@ankara.edu.tr
Öz

Kentleşme dünya genelinde çok hızlı gelişen bir süreçtir. Ancak, kentleşme ile birlikte çevresel, ekolojik ve sosyal yapıdaki kaygılar artmaktadır. Kentleşmenin hızı ve yoğunluğu, arazi kullanım paterninin değişmesinde etkilidir. Değişim sürecinin anlaşılması, kent bölgesindeki arazi değişiminin hızı, yoğunluğu ve izlediği yolun tahmin edilmesi için arazi kullanım değişimine neden olan faktörlerin araştırılması önemlidir. Özellikle kent arazi kullanım değişimini ve ekolojik etkilerinin gelecek trendlerini tahmin etme ve modellemede bu faktörlerin belirlenmesi gereklidir. Ancak bu faktörlerin karmaşık olması ve karşılıklı etkileşimi bunların sistematik olarak analiz edilmelerini gerektirmektedir. Kent sistemi oldukça karmaşık bir yapıya sahiptir. Coğrafi Bilgi Sistemleri (CBS), Uzaktan Algılama (UA) ve özellikle de yeni matematiksel yöntemler sayesinde modelleme tekniklerinde meydana gelen hızlı gelişmeler, çeşitli zamansal ve mekânsal ölçeklerde verilerin elde edilip analiz edilmesini, karmaşık sistemin anlaşılmasını, sözü edilen karmaşıklığın ölçülmesi ve gösterilmesini sağlamıştır. Karmaşık bir kent sisteminin yayılım alanı/alansal büyüklüğü, fiziksel gelişim evreleri ve her bir gelişim evresinin büyüklüğü ve büyüme miktarları kentsel modelleme teknikleri sayesinde en gerçek şekilde ölçülebilmektedir. Aynı zamanda, bu yöntemler mekân analizlerini farklı bir boyuta taşıyarak mekânsal büyüme alanlarının belirlenmesine, gelecek öngörülerin oluşturulmasına büyük katkılar sağlamaktadır.

Anahtar Kelimeler: Kentleşme, kentsel büyüme sistemi, karmaşık kent sistemi, modelleme teknikleri, kent modelleri.

\section{ABSTRACT}

Urbanization is a process increasing progressively worldwide. However, with the urbanization process, concerns have been raising regarding environmental, ecological, and social structure. The speed and intensity of urbanization has effects on changing of land use pattern. Therefore, to be able to understand changing processes and predict change rate, density, and changing pathways in urban area, it is crucial to investigate effects causing changes in land-use pattern. Especially, these factors should be determined for the estimation and modelling of future trends of urban land use changes and its ecological impacts. Because of their complexity and interactions, these factors should be analyzed systematically. Urban system has rather complex structure. Rapid developments in modelling techniques thanks to Geographic Information System (GIS), Remote Sensing (RS) and particularly new mathematical methods provide to obtain and analyze of data in various spatio-temporal scales, understand a complex system or a phenomenon, and measure or show the complexity. Urban modelling techniques may allow to measure more realistic measurements of propagation area of a complex urban system/territorial size, the physical development stages and size of each stage. Besides, these techniques will open new horizons on spatial analyses and contribute to make projections determining in spatial development areas.

Keywords: Urbanization, urban growth system, complex urban systems, modeling techniques, urban models. 


\section{Giriş}

Kentleşme, kırsal alanlara müdahale eden ve sonunda kentlerin yayılmasına veya yoğun nüfus alanlarının oluşmasına neden olan coğrafi dinamiklerle ilişkilidir (Alig ve Healy, 1987; Jacquin vd., 2008). Hızlı kentleşme ve kentsel alan yayılımı dünya çapında bir olgudur. Bu olgunun çevresel, ekolojik ve sosyal yapılar üzerinde önemli etkileri vardır. Arazi kullanım paterninde meydana gelen değişimlerin gösterilmesinde kentleşme hızı ve yoğunluğunun belirlenmesi şarttır. Bu nedenle arazi kullanım dönüşümlerinin etkin bir şekilde araştırılıp planlanması gerekir. Kentleşmiş alanların sürekli büyümesi çevresel olarak hassas alanların dengesinin bozulmasına neden olur (Lee vd., 1999). Kent yapısının bozulması; yoğun trafik, uzun yolculuklar ve geleneksel iş alanların kapanması gibi sorunların yanında, ekonomik fırsat eşitliğinin, boş alanlara erişimin, insanların bir arada yaşamasını sağlayan etkileşimlerin de azalmasına yol açan sosyal problemleri doğurur. Kentin büyüme lokasyonları ve miktarlarının belirlenmesi gelecekte uygun kentsel gelişim planlarının gerçekleştirebilmesini sağlamasının yanında, çevresel ve sosyo-ekonomik açıdan da fayda sağlamaktadır. Bu nedenle, kentsel büyümenin tahmin edilmesinin gerekliliği yaygın olarak kabul edilmektedir (He vd., 2008; Guan vd., 2005).

Arazi kullanım değişim trendlerinin tahmin edilmesi kent planlamasının en önemli konularından birini oluşturmaktadır. Ancak, kent sisteminin birçok bilinmeyen faktör içermesi ve karmaşık yapısı nedeniyle, kentsel gelişimin tahmin edilmesi bilimsel bir anlayış olmadan oldukça zordur. Kentsel büyümenin mekân ve zaman içinde lokasyonu ve miktarını belirlemeyi amaçlayan bilimsel modeller, bilim adamları ve politika yapıcılarına çevresel olarak sürdürülebilir bir gelecek için ampirik ve istatistiksel destek sağlar. Geleneksel istatistiksel verilere ve eski haritalara dayalı yöntemler, hızlı kentleşme sürecine ait dinamik bilgileri etkin bir şekilde analiz etmek ve mekânın heterojen yapısını açıklayabilmek çoğunlukla olanaklı değildir. Coğrafi Bilgi Sistemleri (CBS), Uzaktan Algılama (UA) ve özellikle de karmaşık ve doğrusal olmayan teorilerde meydana gelen hızlı gelişmeler yeni modellerin oluşturulmasını sağlamıştır. Bu teknolojik gelişmeler sayesinde karmaşık kentsel sistemlerin zamansal ve mekânsal ölçekte değişimin, bu değişimin yönü analiz edilebilir hale gelmiştir. Kent plancıları, ekonomistler ve çevre bilimcilerinin kullanacağı güçlü ve güvenilir araçlar olan çok sayıda kentsel büyüme modelleri geliştirilmiştir. Geliştirilen bu modellerin amacı, belli bir kent alanında ve belirlenmiş bir zaman diliminde kent yapısı değişiminin sistematik olarak incelenmesi, mekân analizlerini farklı bir boyuta taşıyarak mekânsal büyüme alanların belirlenmesi ve gelecek öngörülerin oluşturulmasını sağlamaktır. Bu modellerle, kentin gelişimi ile ilgili kent büyüme sistemi nedir? Kent büyümesi nerede gerçekleşmektedir? Bu karmaşık sistemler neden ve nasıl meydana gelmektedir? Kentteki yapısal değişim nasıl tanımlanır? Gelişmeye neden olan itici güçlerin yönü ve miktarı nasıl hesaplanır? Kent büyümesini etkileyen ana itici güçler nelerdir? Kent politikalarının rolü ne ölçüde etkilidir? Çeşitli senaryolara göre kent gelecekte nasıl şekillenecektir? gibi soruların cevapları verilebilir. Sonuç olarak, karmaşık bir kent sisteminin yayılım alanı/alansal büyüklüğü, fiziksel gelişim evreleri ve her bir gelişim evresinin büyüklüğü ve büyüme miktarları kentsel modelleme teknikleri sayesinde gerçek şekilde ölçülebilmekte ve doğruluğu gösterilebilmektedir.

Bu çalışmada, kentsel büyüme ve karmaşık kent sistemi, kent sistemindeki karmaşıklığın kaynağı ve hesaplanması, kentsel büyüme dinamikleri kavramları ile kent büyüme teknikleri açıklanmaktadır. Son yıllarda hızla gelişme gösteren yeni kent modellerinin karmaşık kent sistemleri üzerine yapılmış çalışmalardan örnekler verilerek başvurulan bu tekniklerin karmaşık kent sistemi üzerine faydaları belirtilmiştir.

\section{Kentsel Büyüme ve Karmaşık Kent Sistemi}

Kentsel büyüme; fiziksel, çevresel ve sosyo-ekonomik nedenlere bağımlı olduğu için dinamik, doğrusal olmayan ve karmaşık bir yapıya sahip, ölçülmesi zor bir sistemdir. Kent sisteminin karmaşık yapısının anlaşılması için bu yapının özelliklerinin ortaya çıkarılması gerekmektedir. Karmaşık sistemler, çok sayıda elemanın birbiriyle etkileştiği ve elemanları arasında doğrusal olmayan ilişkilerin bulunduğu, çevreyle etkileşim içinde olan zor sistemlerdir. Wolfram (1988) karmaşık sistemleri şu şekilde açıklamıştır:

- İlişkiler doğrusal değildir; karmaşık sistemdeki çok küçük, önemsiz gibi görünen ve çoğu zaman dikkate alınmayan bir etki beklenmeyen büyük sonuçlar yaratmaktadır. Bir takım zincirleme olaylarla küçük değişiklikler büyük ve önemli sorunlar haline gelebilmektedir.

- Açık sistemlerdir; karmaşık sistemler bu özelliğinden dolayı dış etkilere açıktır. Sistemde tam bir denge sağlanmamıştır.

- Geri besleme halkaları; sistemde bulunan elemanlar sistemi oluşturan diğer parametrelerden etkilenirler. $\mathrm{Bu}$ etki elamanın kendini değiştirmesi şeklinde gerçekleşir.

- Geçmiş; karmaşık sistemler dinamiktir ve zamana bağlı olarak değişirler. Sistemlerin önceki durumunun mevcut durum üzerine etkisi olabilir. Sistemin zaman içindeki gelişimini tam olarak belirleyebilmek için başlangıç değerlerini bilmek gerekir.

- Birbiri içine geçmiş; karmaşık sistemi oluşturan bileşenlerinin her biri kendi başına karmaşık bir sistem olabilir. Örneğin, kentler alt bölgelerden, alt bölgeler kendi içerisinde birbirinden farklı alt sistemlerden ve bunlar arasındaki etkileşimi sağlayan karmaşık sistemlerden oluşur.

- Sınır durumu; karmaşık bir sistemin sınırını belirlemek zordur. Sınır konusunda karar kesinlikle gözlemci tarafından verilir.

Karmaşık bir sistemdeki kentsel büyüme, fiziksel yayılım ve fonksiyonel değişmeden oluşmaktadır. Fiziksel yayılım mekândaki değişimi (inşa olmayan alandan, kent alanına 
dönüşüm), fonksiyonel değişim arazi kullanımındaki önemli aktivitelerin değişimini gösterir. Dolayısıyla, mekân ve aktivite kentsel büyüme sisteminin iki temel elemanıdır.

Kentsel büyümenin gelişimi, Planlanmış Şehir Sistemi (P), Gelişmiş Kent (U) ve Gelişebilir Kent Dışı Sistem (N) ile yakından ilişkilidir (Şekil 1). $\boldsymbol{P}$, mekânsal planlama neticesinde oluşan mekânsal ve kavramsal bir yapıdır. Gelecekteki kentsel büyüme için gerekli olan organize olmuş mekân ve aktiviteleri oluşturur. $\boldsymbol{U}$ ( $t_{1}$ zamanında) karmaşık sosyoekonomik sistemlerden oluşmaktadır. Bu kavram alandan ziyade kent alanlarındaki sosyo-ekonomik aktiviteleri ifade eder. $\boldsymbol{N}$, çeşitli ekolojik birimleri (su kütlesi, orman vs.) ve tarım alanlarını ifade eder. Mekânda $t_{2}$ zamanına kadar gerçekleşen kentsel büyümeyi gösterir (Şekil 1). Kentsel büyüme $(\boldsymbol{G})$, bu üç sistem $(\boldsymbol{U}, \boldsymbol{N}, \boldsymbol{P})$ arasındaki etkileşimlerden (sadece $t_{1}$ zamanından, $t_{2}$ zamanına kadar) meydana gelen bir yapı olarak tanımlanabilir. Şekil 1'de gösterilen ince oklar üç sistem arasındaki etkileşimi, daireler arasındaki kalın hatlar üç sistemin kentsel büyümeye olan katkısını göstermektedir. Sistem $\boldsymbol{P}$, planlama kontrolü ve $\boldsymbol{G}$ için gereksinimlere; Sistem $\boldsymbol{N}$, gelişebilir arazilere; Sistem $\boldsymbol{U}$, $\boldsymbol{G}^{\prime}$ nin büyümesini tetikleyen faktörlere ve aktivitelere katkı sağlamaktadır. Kısaca kentsel büyüme bu üç sistemin birbirini etkilemesi sonucu şekillenmiş bir sistemdir. Sistemler arasındaki bu etkileşim açık, doğrusal olmayan ve dinamik özelliklere sahiptir. Bu özelliklerin ve etkileşimin anlaşılması kentsel büyümenin çözümlenmesini sağlar.

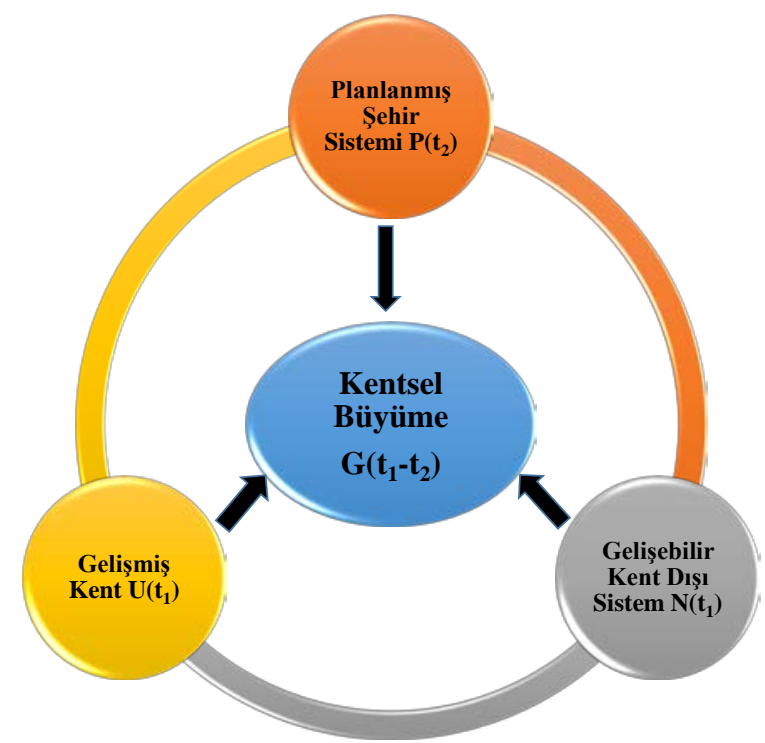

Şekil 1. Belirli bir zamanda $\left(t_{1}-t_{2}\right)$ meydana gelen kentsel büyüme.

Figure 1. Urban growth occured in a certain time ( $\left.t_{1}-t_{2}\right)$.

Kentsel büyüme politika, aktör, davranış, süreç ve patern olmak üzere beş seviyede özetlenebilir. Politika, kentsel büyümeyi etkileyen en büyük itici güç olup, en üst seviyede yer alır. Aktör, sosyo-ekonomik aktiviteleri ile kentsel büyümeye sebep olan insanlardır. Davranış, kentsel büyümeye dâhil olan aktörlerin hareketlerini gösterir. Süreç, kentsel büyüme dinamiklerini gösterir. Patern, direkt olarak gözlenebilir ve kentsel büyümeye sebep olan en düşük seviye olarak bilinir. Sürecin anlık fotoğrafıdır. Bu seviyeler kullanılarak oluşturulan modellemede en alt seviye olan paternden en üst seviye olan politika seviyesine doğru sıra takip edilmek zorundadır. Hiyerarşi teorisine göre, belirtilen sıradaki seviyenin anlaşılması, birbirleriyle yakın ilişkilerinden dolayı, bir alt ve bir üst seviyenin de dikkate alınmasını zorunlu kılar. Örneğin, sürecin anlaşılması patern ve davranışın da düşünülmesini gerektirir. Patern, sürecin anlık durumunu gösterirken, davranış sürecin karar verme kaynağıdır.

\section{Kent Sistemindeki Karmaşıklığın Kaynağı ve Hesaplan- ması}

Kentsel büyümenin mekânsal, zamansal ve karar verme değişimi, sosyal, ekonomik, ekolojik ve çevre çeşitliliğinden kaynaklanmaktadır. Bu çeşitlilik kentsel büyümenin karmaşık paternini, davranışını ve sürecini oluşturmaktadır. Bu durum karmaşık yapının en iyi göstergesidir. Kentsel büyüme farklı ölçeklerdeki projelerden oluşur. Büyük ölçekli projeler; büyük yatırım, uzun vadeli inşaat ve çok sayıda aktörlerle karakterize edilir. Havaalanları, sanayi bölgeleri ve üniversite alanları büyük ölçekli projelere örnek verilebilir. Küçük ölçekli projeler ise hızlı yapılaşma, düşük yatırım ve daha az aktörlerle karakterize edilir. Konut ve küçük işyerleri örnek olarak verilebilir.

Kentsel büyümeyi oluşturan üç sistem, büyük ve küçük ölçekli projeler arasında olan karşılıklı etkileşimler sistemlerdeki daha yoğun bir enerji, bilgi akışı ve aktörlerin ortaya çıkmasına neden olur. Bütün bunlar kentsel büyümenin doğasında olan karmaşık kaynaklardır. Kent politikalarında karar verme süreçlerindeki kantitatif ölçümler, modellemenin doğruluğunu ve daha ileride üretilecek olan politikaları etkileyen önemli bir role sahiptir. Bir sistemin karmaşıklığının etkin olarak ölçülmesi karmaşıklık teorisi içinde bile çözülememiş bir konu olarak kalmıştır. Kentsel büyümede böyle karmaşıklıklar: mekânsal, zamansal ve karar verme hesaplamaları olarak incelenir. CBS ve UA tekniklerine dayalı özel analizler gerektiren hesaplamalar için çok sayıda gösterge geliştirilmiş olsa da, bunlar çoklu karmaşıkIığın tüm özelliklerini tam anlamıyla açıklayamamaktadır. $\mathrm{Bu}$ nedenle yeni geliştirilen modeller mekânsal, zamansal ve karar verme karmaşıklığını çözümlemek için geliştirilmişlerdir.

Mekânsal Karmaşıklık: Mekânsal modellemenin ilk adımı mekânsal karmaşıklığı tanımaktır. Mekânsal karmaşıklık; mekânsal bağımlılık, çok ölçekli durumlar ve yapısal veya işlevsel karmaşıklıktan oluşmaktadır.

Mekânsal bağımlılık, mekândaki bir nokta ile komşu bir nokta arasındaki işlevsel ilişkiler olarak tanımlanır. Bu ilişkiler kent gelişim sistemi içerisinde pozitif ve negatif etkilere neden olur. Pozitif etkilere örnek ulaşım altyapısı ile gelişmiş kent alanı verilebilir. Engebeli araziler ve gelişmeye uygun olmayan araziler örneğin derin göller gibi yerler negatif etkilere örnek olarak düşünülebilir.

Zamansal Karmaşıklık: Kentsel büyümenin dinamik sürecinin anlaşılmasında zaman ölçeği yüksek oranda etkileyici 
bir faktördür. Kent sistemleri karmaşıktır ve tam manasıyla dönüşümü tahmin edilemez (Yeh ve Li, 2001). Kentin gelişim süreci bilinmeyen başlangıç koşullarına (savaş, doğal afet, hükümetin yeni politikaları) oldukça hassastır. Genellikle bu koşulların özellikle kantitatif açıdan tahmin edilmesi mümkün olamamaktadır. Kentsel büyümenin doğrusal olmaması patern, süreç ve davranışların zaman içinde çeşitli özellikler göstermesiyle sonuçlanır. Özellikle de uzun dönemde kentsel büyüme belirsiz, tahmin edilemez veya hatta kaotik olarak düşünülebilir. Farklı seviyedeki aktörler, farklı zamansal ölçekte karar verme davranışları gösterirler.

Kent planlaması ve yönetimi açısından kentsel büyümenin dinamik süreçlerini anlamak çeşitli periyodlarda zamansal karşılaştırmayı gerektirir. Bu tarz karşılaştırmalar, plancıların değişen çevreye uyum sağlaması için planlama projelerini modifiye etmelerine veya güncellemelerine olanak sağlar.

Karar verme karmaşıklığı: Kantitatif coğrafyacılara göre, kentin mekânsal yapısı, çoklu karar verme süreçlerinin bir araya gelmesi sonucu oluşur (Allen ve Sanglier, 1981). Karar verme karmaşıklığı; karar verme süreci ve birimi, aktörleri veya karar vericilerinden oluşur. Kentsel büyümenin dinamik sürecinin anlaşılması karar verme süreci ile olan bağlantı temeli üzerine olmalıdır. Çünkü modellerin son kullanıcıları farklı seviyedeki karar vericilerdir. Büyük ölçekli projelerin karar verme birimi ve süreci küçük ölçeklilere göre nispeten karmaşıktır. Büyük ölçekli projeler daha fazla aktör veya karar verici içerir. Buna karşılık küçük bir dükkân yalnızca bir kişinin kararına ihtiyaç duyar. Büyük ölçekli projeler diğerleriyle karşılaştırıldığında miktar olarak sınırlı olup karar verme süreci daha iyi planlanmıştır. Küçük ölçekli projeler miktar olarak fazla, karar verme aşaması daha belirsiz, dinamik ve daha az organize olmuşlardır.

\section{Kentsel Büyüme Dinamikleri}

Kent arazi kullanım dinamikleri, bireylerin, kamu ve özel teşebbüslerin belirli bir zaman diliminde eş zamanlı olarak yaptıkları faaliyetlerin doğrudan sonucudur. Tüm bu etkiler kentlerin sürekli olarak gelişmesine katkı sağlar. Tüm bu etkilerin eş zamanlı olarak meydana geldiği düşünüldüğünde kentsel yerleşimin karmaşıklığı şaşırtıcı değildir. Kentsel aktiviteler için birçok arazi kullanım faktörleri belirlenmiştir. Bunlar beş grupta toplanabilir:

1) Çevresel özellikler

2) Yerel-ölçek komşu özellikleri

3) Kentlerin mekânsal özellikleri

4) Kent ve bölgesel planlama politikaları

5) Bireysel tercihler ile ilgili faktörler, ekonomik gelişmişlik düzeyi, sosyo-ekonomik ve politik sistemler

Çevresel özellikleri oluşturan ilk grup, kentsel büyümeyi etkileyen tehditler (eğim, doğal afete eğilimi olan alanlar, doğal engeller) olarak gösterilebilir. İkinci grup, Tobler'in (1970) "her şey başka her şeyle ilişkilidir, yakın olan şeyler uzak olanlara göre daha çok ilişkilidir" olduğunu ifade eden coğrafyanın ilk kanununa dayalıdır. Bu durum kent arazi kullanımının mevcut hali ile geçmişteki arazi kullanım paterni ve dinamikleri arasındaki ilişkiyle açıklanabilir. Üçüncü grupta yer alan faktörler, kentin mekânsal özellikleriyle (kent merkezinden uzaklık, ulaşılabilirlik, ulaşım ağı) ilişkilidir. Örneğin, yeni yolların açılması yeni arazi kullanım alanlarını harekete geçirici önemli bir etkendir. Dördüncü grup, kent ve bölgesel planlama politikalarıyla ilgilidir. Beşinci grup ise, bireysel tercihlerden, ekonomik gelişmişlik seviyesinden, sosyo-ekonomik ve politik sistemlerden oluşur. Bu grupta yer alan özellikler anlaşılması ve modellenmesi en karmaşık faktörlerdir. Aynı zamanda bu grupta yer alan faktörler karar verme süreçleri ile yakın ilişkiye sahiptirler.

\section{KENT MODELLEME TEKNIKLERi}

Kentleşme ve sonuçlarının etkileri birçok disiplinin araştırma konusu olmuştur. Coğrafyacılar, plancılar, ekonomistler ve sosyal bilimciler, uzun zamandan beri kentlerin gelişimini ve morfolojisini araştırmışlardır. Kentsel büyüme modelleri kentteki değişimin anlaşılması, etkili bir çevre planlaması, gelişme planları, kentsel politikaların oluşturulması, kent plancıları ile politikacıların kent geleceğinin olası gelişimini tahmin etme ve geliştirmesine olanak sağlamaktadır. Genel olarak model, yaşadığımız dünyayı daha iyi kavrayabilmek amacıyla gerçeğin soyutlanması şeklinde tanımlanabilir. Modeller gerçek ve teori, geçmiş ve gelecek arasında tıpkı bir ara bulucu gibi merkezi bir rol oynamaktadır (Batty, 2007). Kent üzerine strateji ve plan geliştirirken kentsel büyümenin karmaşık yapısını anlamak ve sorunlarını hafifletmek önemli bir yer tutmaktadır. Bu sebeple, araştırıcılar kentsel büyümenin tahmin edilmesi ve açıklanması üzerine birçok modelleme yaklaşımları geliştirmişlerdir (Wu, 2005). Markov Chain analizi, Çoklu Regresyon Analizi, Temel Bileşen Analizleri, Faktör Analizleri ve Lojistik Regresyon Analizleri gibi geleneksel istatistik modelleri sosyo-ekonomik aktiviteleri yorumlamada oldukça başarılıdırlar. Markov Chain (Lopez vd., 2001), Lojistik Regresyon (Wu ve Yeh, 1997) gibi istatistik metotların çeşitli güçlü ve zayıf yönleriyle kentsel büyüme modelleri için oldukça yaygın bir kullanıma sahip modellerdir. Lopez vd. (2001) Meksika'da Morelia kenti için yapmış oldukları çalışmalarında kentin arazi kullanım değişimi ve arazi örtüsü tahmini üzerine bir model geliştirmiştir. Bu çalışmada yazarlar, Markov geçiş matrislerinin en güçlü kullanım alanlarının tahmin seviyesinden ziyade açıklayıcı olduğu sonucuna varmışlardır. Kent ve nüfus büyümesi arasındaki doğrusal regresyon Morelia kenti için kentsel büyümeyi ortaya koyan kaba bir tahmin olmuştur. Wu ve Yeh (1997) 19781987 ve 1987-1992 tarihlerine ait hava fotoğraflarından kent büyüme paternlerini modellemek üzere Lojistik Regresyon Analizi yöntemini kullanmışlardır. Bu iki dönem boyunca arazi gelişiminin temel belirleyicilerinde önemli ölçüde bir değişme olduğunu, çeşitli faktörlerin arazi gelişimi sürecinde rollerini değiştirdiğini ortaya koymuşlardır. Çalışmaları kentsel gelişmeyi yorumlamada lojistik regresyonun güçlü bir kapasiteye sahip olduğunu göstermektedir. Cheng ve Masser (2003), çalışmalarında kentsel patern 
analizlerinde yaygın olarak kullanılan üç lineer modeli (Lineer Regresyon, Lojistik Regresyon ve Log-lineer Regresyon) karşılaştırmıştır. Sonuçta lojistik regresyonun genel olarak bağımlı ve açıklayıcı değişken tiplerinde, hesaplama yönteminde ve normalite varsayımlarında daha avantajlı olduğunu belirtmişlerdir. Ancak, bu geleneksel regresyonlar kentsel büyümenin mekâna bağlı olarak değişken olmadığını farz etmektedir. Bu şekildeki global modeller kullanılarak, mekânda homojen olmayan ilişkilerin yetersiz bir şekilde basitleştirilmesine gidilmiş olabilir. Bu sebeple, tekalgoritmalı usule dayanan bu yöntemlerin mekânın heterojen yapısını açıklayabilme kabiliyeti oldukça sınırlıdır.

\section{Kent Model ve Tekniklerinde Yeni Yaklaşımlar}

Hızla büyümeye maruz kalan kent sistemlerinin karmaşık bir yapı göstermesinden dolayı, geleneksel istatistik yöntemleri, zamansal ve mekânsal verileri modellemede yetersiz kalmaktadır. Bunun başlıca nedenleri; zamansal ve mekânsal verilerin normal dağılım göstermemesi, bağımlı ve bağımsız değişkenlerin hata yapısı, model doğrusallığ gibi temel varsayımların ihmalidir. Bu nedenle daha gerçekçi ampirik yöntemler, CBS, UA ve özellikle de yeni matematiksel yöntemler ile çok sayıda kentsel büyüme modelleri geliştirilmiştir. Karmaşıklığın ölçülmesi ve gösterilmesi bu modeller sayesinde daha güçlü ve güvenilir olmuştur. Bu modellerden başlıcaları; Agent Based Modeling (Ajan Tabanlı Modelleme, ATM), Cellular Automato (Hücresel Otomata, HO), Artificial Neural Network (Yapay Sinir Ağları, YSA) modelleridir.

\section{Ajan tabanlı modelleme (ATM)}

ATM modelleri, sosyal süreçleri karar vermeye dahil etmek ve dinamik sosyo-ekonomik çevresel bir bağlantı kurmak için bireysel karar verme girdilerini ve bunların birbirleriyle etkileşimlerini modelleyebilmektedirler (Matthews vd., 2007). ATM modelleri ilk olarak tarım alanları çalışmalarında uygulanmıştır (Lansing ve Kremer, 1993). Örneğin, tarım politikalarının bölgesel tarım alanlarına etkisini göstermek için bazı araştırmacılar ATM yöntemini kullanmıştır (Berger, 2001; Happe, 2004). Ligtenberg vd. (2004), arazi kullanımı ile ilgili karar verme yollarını bulmak için bir ATM modeli geliştirmişlerdir. Ligmann ve Jankowski (2007), gerçek politika senaryolarını mekânsal olarak açıklayan bir model oluşturmak için ATM yöntemini kullanmışlardır.

ATM'nin bir diğer önemli uygulama alanı, kent sistemlerinde sosyo-ekonomik etkileşimlerin simülasyonunu oluşturmaktır. Brown ve Robinson (2006), kent sistemi içinde yerleşim gelişimini göstermek için ATM yöntemini kullanmışlardır.

\section{Hücresel otomata (HO)}

$\mathrm{HO}$, dünyada yaygın olarak kullanılan bir modeldir. Bu nedenle, çalışmada ayrıntılı olarak açıklanmıştır. HO modeli, karmaşık dinamik sistemlerin simülasyonunda uygulanan mekânsal dinamik modelleme tekniğidir. Bu model, dinamik bir sistemin esaslarını araştırmak, kuramsal uygulama- larda varsayım ve fikirleri test etmek için geliştirilmiştir (Couclelis, 1997; Batty vd., 1999). HO, dinamik bir sürecin modellenmesinde yeni bir düşünce yolu sunar. Aynı zamanda, karmaşık mekânsal bir sistemde karar alma süreçlerini test etmek için bir laboratuvar görevi sağlar.

Arazi değişimini ortaya koyarken mekânsal ve mekânsal olmayan dinamikleri dikkate almak gerekir. HO modeli ile tek başına bu dinamikleri açıklamakta yetersiz kalmaktadır. Bu durumda HO modeli ile ATM modeli birlikte uygulanır. Çünkü ATM, mekânsal modelleme yöntemlerinde modeli tamamlayan ve geliştiren bir özelliğe sahiptir. Böylece HO mekânsal dinamikleri açıklarken, ATM sosyal etkileşimleri göstermektedir.

HO sisteminde mekân, düzenli hücrelere bölünmektedir. Her hücrenin durumu lokal kurallara göre güncellenir. Bunun anlamı, verilen bir zamandaki hücrenin durumu, hücrenin kendi durumuna ve bir önceki zamandaki komşu hücrelerin durumlarına göre tanımlanmasıdır (Wolfram, 1984). Tüm hücrelerin durumu aynı anda güncellenir. Sistemin davranışı birleşik lokal geçiş kurallarının etkisiyle tanımlanır. Böylece, sistemin durumu farklı zaman basamaklarında ilerlemektedir. Basit bir HO modeli hücre, durum, komşu, geçiş kuralı ve zaman olmak üzere beş farklı bileşenden oluşmaktadır.

Hücresel mekânda basit bir mekânsal birim olan hücre, farklı boyutlarda çeşitli formlara sahiptir. Örneğin iki boyutlu HO tipi, kentsel büyüme ve arazi kullanım değişimlerinin modellenmesinde en yaygın kullanıma sahip formlardandır. Tek boyutlu HO tipi ise, kent trafiği modellenmesi gibi doğrusal nesneler üzerinde yapılan çalışmalar için geliştirilmiştir. Petek veya üç boyutlu düzenlemeler HO'nun diğer başka formlarını oluşturmaktadır. Örneğin, kent alanlarında binaların yüksekliklerini göstermek HO'nun üç boyutlu formu ile sağlanabilir. Ancak, modelin dizayn ve inşasının zorluğundan dolayı, bu hücresel düzenlemeler daha az popülerdir ve kent modelleme pratiğinde gelişememiştir.

HO'nun diğer bileşeni olan durum, sistemin özelliklerini tanımlar. Her hücre yalnız bir durumdan oluşmaktadır. Örneğin, açık-kapalı, 1-0, gelişme var-yok gibi bu durum bilgisi ikili (binary) veriden oluşabildiği gibi hücrelerin durumları arazi örtüsü ve arazi kullanım tiplerini tanımlayan kent, yöre kent, kırsal vb. fonksiyonlarda durum bilgisi olarak tanımlanabilir.

HO'da komşuluk, hücrenin etkileşimde olduğu hücreleri ifade etmektedir. Komşuluğun the von Neumann Neighbourhood (dört hücre) ve the Moorre Neighbourhood (sekiz hücre) olmak üzere iki temel tipi vardır. Komşuluğun ilk tipi bir hücrenin kuzey, güney, doğu ve batı olmak üzere dört hücreden oluşmaktadır. İkinci tip, bu 4 hücrenin yanında aynı zamanda kuzey-batı, kuzey-doğu, güney-doğu ve güney-batı yönlerini de içermektedir. Sorgulanan hücrenin belli mesafedeki daire içindeki komşuluğu gibi komşuluğun diğer türleri kent planlamasında ayrıca kullanılmaktadır (White ve Engelen, 1994; White vd., 1997). 
Bir hücrenin durumunun mevcut durumu ve komşu hücrelerin durumuna göre nasıl değişeceğini tanımlayan geçiş kuralları HO'nun önemli bir bileşenini oluşturmaktadır. Bu geçiş kuralları modellenen sistemin sürecini göstermektedir. Geçiş kuralları düzenlidir ve sistemin bütün hücrelerine eşzamanlı uygulanmaktadır.

HO'nun bir diğer bileşeni olan zaman, geçiş kuralları ile bağlantı içerisinde çalışır. Geçiş kurallarına göre durumunu ayarlayacak olan hücre belli bir zaman aralığına bağlıdır ve zaman geçtikçe hücrenin durumu değişebilir.

Karmaşık kent sistemlerinin HO yardımıyla modellenmesi 1980'lerin sonundan bu yana çok hızlı bir gelişme göstermiştir. Bu konuyla ilgili çok sayıda çalışma mevcuttur (White ve Engelen, 1993; Batty ve Xie, 1994; Clarke ve Gaydos, 1998). Özellikle kent alanlarındaki arazi kullanımı ve arazi örtüsü değişiminin tahmin edilmesinde ve simülasyonunda kullanılan kentsel HO modelleri, temel HO kavramlarından daha karmaşık bir yapıya sahiptir. Komşuluk paternleri, dönüşüm kuralları, diğer sosyo-ekonomik modellerle olan bağlantıları kentsel HO'yu daha gelişmiş ve sofistike kılar (Benenson ve Torrens, 2004). HO'nun en önemli özelliklerinden biri, basit dönüşüm kuralları ile karmaşık mekânsal paternlerin simülasyonunda kullanılıyor olmasıdır. Kent çalışmalarında kullanılan en az üç tip $\mathrm{HO}$ modeli vardır. Bu modellerin birincisi, kent teorileri ile açıklanabilen kent dinamiklerinin simülasyonunu oluşturan tiptir. Bu model, gerçek verileri kullanmadan kuramsal kentler için varsayımların ve fikirlerin test edilmesinde kullanılır. White ve Engelen (1993) kentleşmiş alanların fraktal ve ikili fraktal arazi kullanım yapısını göstermek için $\mathrm{HO}$ modelini kullanmışlardır. Wu (1998) tarafından yapılan çalışmada, bir arada bulunan yerel güçler birleştirilerek kent ve alt birimlerinin simülasyonu oluşturulmuştur.

Kentsel HO modellerinin ikinci tipi gerçek veri seti kullanarak daha gerçekçi kent simülasyonu oluşturmak için geliştirilmiştir. Clarke ve Gaydos (1998) California'nın San Francisco Bay bölgesi ve Doğu Amerika'daki Washington/ Baltimore koridorunda kentsel büyümenin tahmini için bir simülasyon yapmıştır. White vd. (1997) Ohio, Cincinnati kentinin arazi kullanım paterninin simülasyonunu yapmak için bir HO modeli geliştirmiştir. Li ve Yeh (2000) HO ve CBS'yi entegre ederek China, Pearl River Deltası'nda hızlı kentsel büyümenin simülasyonunu yapmıştır. Mevcut kentsel süreçlerin ilerleyen yıllarda da devam edeceği düşünüldüğünde, HO'nun bu tipi, kentsel büyümenin gelecekteki pattern ve yönünü tahmin etmede yaygın bir kullanıma sahip olacaktır. Çünkü HO’nun bu tipi plancı, çevre bilimci vb. gibi kent üzerine çalışan araştırmacılara gelecekteki kentsel büyüme alanlarının nerede olması gerektiği, kentsel büyüme etkilerinin değerlendirilmesi, gelişmeyi destekleyecek yapıların sağlanması ve planların yapılması konularında fayda sağlamaktadır.

Kentsel HO modellerinin üçüncü tipini, planlama amaçlarına dayalı farklı kent formlarını simüle etmek için normatif planlama modellerinin geliştirmesi oluşturmaktadır. Yeh ve Li (2001) plancılar ve karar veren kişiler tarafından belirtilen farklı planlama hedeflerini birleştirerek tek merkezliden çok merkezliğe kentsel büyümenin alternatif kentsel formlarını simüle etmek için $\mathrm{HO}$ modelinin bu tipini kullanmışlardır. Ward vd. (2000) geliştirdiği HO modelini Doğu Avustralya'nın hızlı kentleşme gösteren sahil bölgesi Gold Coast'a uygulamıştır. Bu çalışma ile HO'nun gerçek bir gelişme kadar, planlanmış bir gelişmeyi de simüle edebildiğini göstermişlerdir.

HO'nun kent modellemede birçok avantajı olmasına karşın, parametre değerlerinin (geçiş kuralları) nasıl belirlenebileceği büyük bir problem oluşturmaktadır. Geçmişte uygulanan $\mathrm{HO}$ modelleri sadece kırsaldan kent arazi kullanımına geçiş ve kent büyümelerinin simülasyonuna yoğunlaşmış çalışmalardır. Kentsel büyümeyi simüle etmek göreceli olarak daha kolay gözükmektedir. Çünkü HO modelleri önceleri sadece ikili sisteme (kentsel/kentsel olmayan) göre şekillenmekteydi. Ancak, ilerleyen çalışmalarda modelin içine boş alanlar, yerleşim alanları, ticari alanlar ve endüstriyel alanlar gibi çoklu arazi kullanım tiplerinin de dâhil edilmesiyle HO modellerinin karmaşık kent sistemlerinin simülasyonunu gerçekleştirebilmesi mümkün olmuştur. Karmaşık kent sistemleri üzerine yapılan çalışmalarda çok sayıda mekânsal değişkenlere ihtiyaç vardır. Her bir mekânsal değişkenin simülasyona katkısı onunla ilişkili ağırlığı veya parametresi ile sayısallaştırılır. Bu nedenle simülasyon gerçekleştirilmeden önce belirlenmesi gereken birçok parametre vardır. Parametrenin değeri değişkenin önemini göstermektedir ve simülasyonun sonuçları üzerinde büyük bir etkisi vardır. Değişkenin büyük bir parametre değeri ile ilişkili olması diğer değişkenlerden daha önemli olduğu anlamına gelmektedir. Parametrelerin farklı kombinasyonları tamamıla birbirinden farklı kentsel formların oluşmasına neden olmaktadır (Batty vd., 1999; Yeh ve Li, 2001).

Gerçek kentlerin simülasyonunda kalibrasyon süreçleri, gerçek ve doğru bir kentsel büyüme sağlamak için uygun parametre değerlerini bulmayı amaçlar. HO modellerinin daha gerçekçi simülasyon sonuçları verebilmesi için kalibrasyon süreçlerinde uygun parametre değerlerinin tanımlanması gerekmektedir. Karmaşık mekânsal sistemin simülasyonu için çoğu doğrusal olmayan ilişkiye sahip çok fazla değişken hatta yüzlercesi kullanılmaktadır (White ve Engelen, 1994). Kentsel büyümenin karmaşıklığından dolayı evrensel olarak kabul edilebilen bir kalibrasyon metodu yoktur. Örneğin, Wu ve Webster (1998) parametre değerlerini tanımlamak için çok ölçülü değerlendirme yöntemi kullanmışlardır. Clarke vd. (1997) görünür testlerin, parametre ayarlarının kaba tahminlerini yapmada ve parametre oranlarını tespit etmede çok faydalı olduklarını söylemişlerdir. Clarke ve Gaydos (1998) kalibrasyonun beklenene karşılık gözlenenin istatistiksel olarak test edilmesiyle gerçekleştirilebileceğini önermişlerdir. Metod, parametreler yardımıyla en iyi modeli bulmasına imkân verir. Bu parametreleri daha sonra tahmin etmede kullanılmaktadırlar. Farklı parametre değerlerine sahip çok fazla olası kombinasyonlar vardır. 


\section{Yapay sinir ağları (YSA)}

YSA gözlem verilerini eğitebilen bir metodtur. Bu metod aynı zamanda yukarıda bahsedilen HO tabanlı bir YSA kent planlaması çalışmasında gelişme alternatiflerini simüle etmek için geliştirilebilmektedir. Planlama senaryolarının üretimi ve düzenlemesi kent planlamasında önemli bir hedeftir. Gelişme planlarını meydana getirebilmek ve simüle edebilmek için YSA'nın öğrenmesini sağlamak mümkündür. Li ve Yeh (2001) yaptıkları çalışmada gerçek kentlerin simülasyonunda YSA metodunun ne kadar etkili olduğunu göstermişlerdir.

CBS ve UA verileri YSA yönteminin öğretilmesi için kullanılmaktadırlar. Orijinal eğitim verileri kullanılırken, model geçmiş trendlere dayalı büyümeyi simüle edebilmektedir. YSA yönteminin geçmişteki istenmeyen büyümeleri hatırlaması için öğrenme verilerinin düzenlenmesine ihtiyaç vardır. Öğrenme süreci geriye yayılım (back-propagation) algoritmaları kullanıldığı için güvenilirdir. YSA'nın geleneksel HO yöntemlerine göre iki avantajı vardır. Belirleyici parametre değerlerindeki belirsizlikleri azaltır ve gelişim alternatiflerini oluştururken parametre değerlerinin nasıl belirleneceğini ortaya koyar.

YSA, matematiksel modellerle insan beynini taklit etmek için geliştirilmiştir. Bilgi işleme, öğrenme ve adaptasyon gibi görevleri yerine getirebilen insanların beynindeki biyolojik yapılardan esinlenilerek tasarlanmış bir sistemdir. YSA hesaplama gücünü, bir bütün olarak paralel işlem yapabilmesi, öğrenme ve bundan dolayı da genelleme yapma kapasitesinden almaktadır. Bilgi işleme kabiliyetleri YSA sisteminin karmaşık problemleri çözmesini mümkün kılmaktadır.

YSA, veriyi işlemede çok basit bir yapıya sahiptir. YSA'nın temel elemanı bir bilgi işleme ünitesi olan "nöron"dur. Nöronlar ağ oluşturmak için birbirlerine ağırlıklı linkler (weighted linked) ile bağlıdır (Şekil 2).

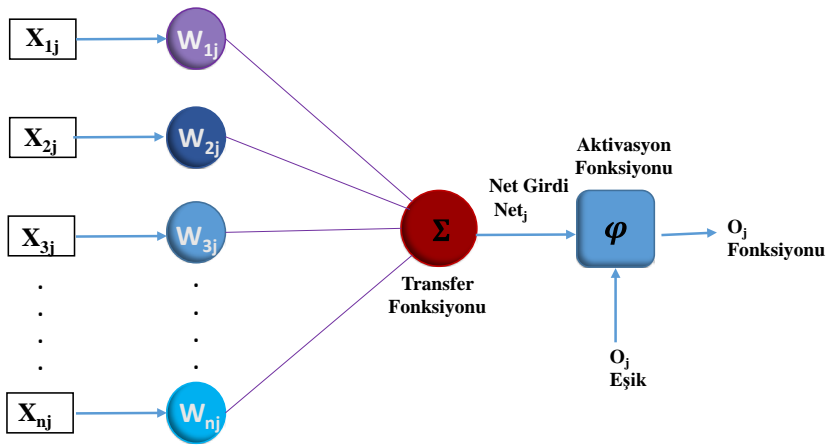

Şekil 2. Nöron modeli (Krenker vd., 2011 çalışmasından uyarlanmıştır).

Figure 2. Neuron model.

YSA, genellikle farklı sayılarda nöronları içeren üç tabakadan (layer) oluşur: girdi tabakası (input layer), saklı tabaka (hidden layer), çıktı tabakası (output layer). Ağ içinde girdi tabakasındaki nöronlar haricinde tüm nöronlar, kendisine bağlı ağırlıklı linklerden gelen girdileri toplar ve toplanan değerlere cevap olarak bir aktivasyon oluşturur. Aktivasyon genellikle sigmoid fonksiyon formunda oluşturulur (Şekil 3). Bu aktivasyon diğer tabakadaki nöronlara girdi olarak iletilir (feed forward).

Nöronlar arasındaki etkileşimi gösteren fonksiyon;

$$
n e t_{j}=\sum_{i} w_{i, j} I_{i}
$$

$l_{i}$, iletiyi gönderen i nöronunun girdi sinyalini, net $_{j}$ diğer tabakadaki alıcı nöron j için toplam sinyal/girdiyi, $w_{i j}$ ağırlık (weight)'i ifade eder. Alıc nöron netj sinyal/girdisine cevap olarak oluşturduğu aktivasyon ise;

$$
f(n e t)=\frac{1}{1+\mathrm{e}^{-n e t} j}
$$

sigmoid fonksiyon ile ifade edilir (Şekil 4).

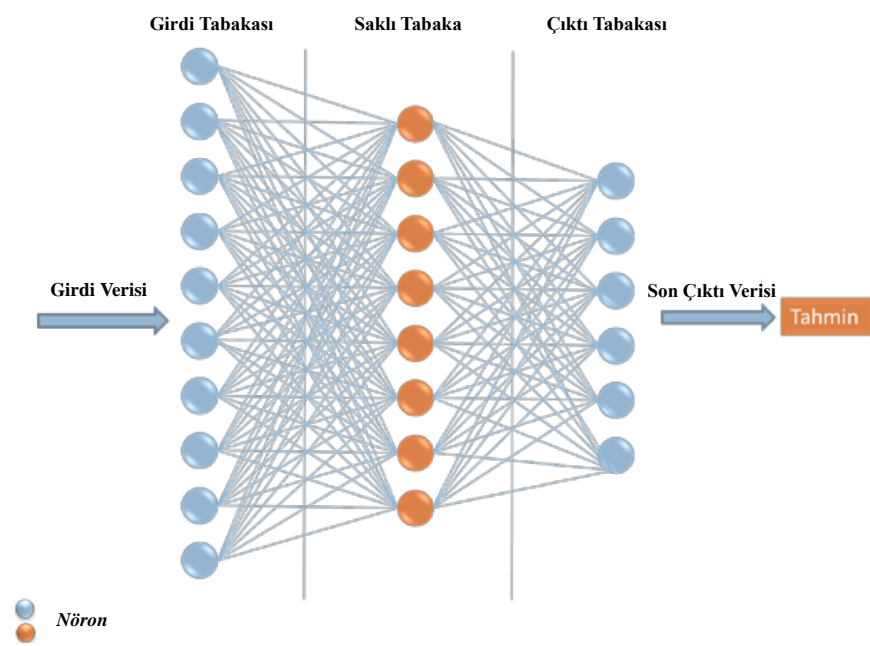

Şekil 3. Nöral ağ yapısı (Maithani, 2009 makalesinden uyarlanmıştır).

Figure 3. Neural network structure.

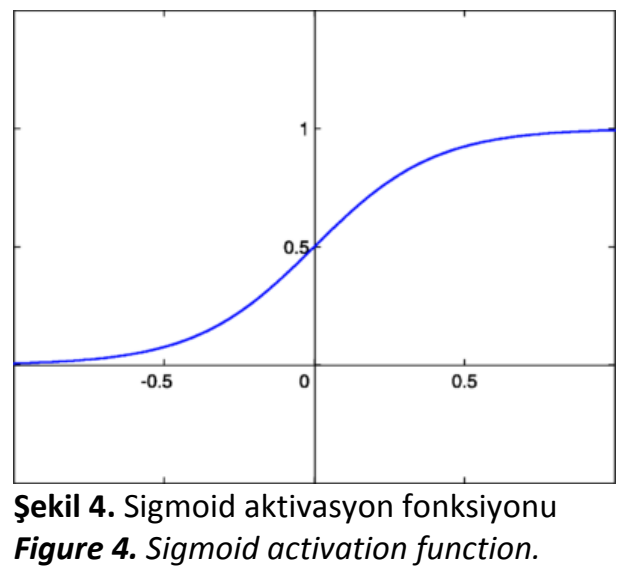

Yukarıda verilen iki denklem, girdiyi/sinyali işlemek için tekrar tekrar kullanılır. Bu süreç (feed-forward) son sinyal/girdi-çıktı tabakasına ulaşıncaya kadar devam eder. Öğrenme sürecinde, ağın gerçek çıktı değerleri ile arzu edilen çıktı değerleri arasındaki farkı minimum seviyeye getirmek için ağ içindeki ağılıkların değerleri tekrar düzenlenir. Bir ağda bulunan saklı nöronların sayısı genellikle ağ hatası varyansının değişimini en aza indirecek şekilde seçilir (Bishop, 1995). 
YSA yöntemindeki öğrenme süreci, veri seti için arzu edilen değerlere olabildiğince en yakın tahminleri yapma yeteneğine sahiptir. Tahmin yüzeyi, belirgin bir şekilde doğrusal olmayan niteliktedir. Bu özellik, popüler regresyon modellerinin doğrusal yüzeylerine göre daha üstündür (Lloyd, 1997), (Şekil 5). YSA yöntemi doğrusal olmayan özellikleri haritalama kapasitesine sahiptir. Bu sebeple, deneme ya da öğrenme yoluyla bir paterni sınıflandırma ve tanımada oldukça faydalı bir araç olarak kullanılabilmektedir. Yapılan çalışmalar YSA sisteminin konvansiyonel istatistik yöntemlerine göre daha üstün bir performans sağladığını göstermiştir; çünkü YSA mekânsal verinin belirsizliğini çok iyi bir şekilde analiz edebilme yeteneğine sahiptir (Openshaw, 1993; Fischer ve Gopal, 1994).

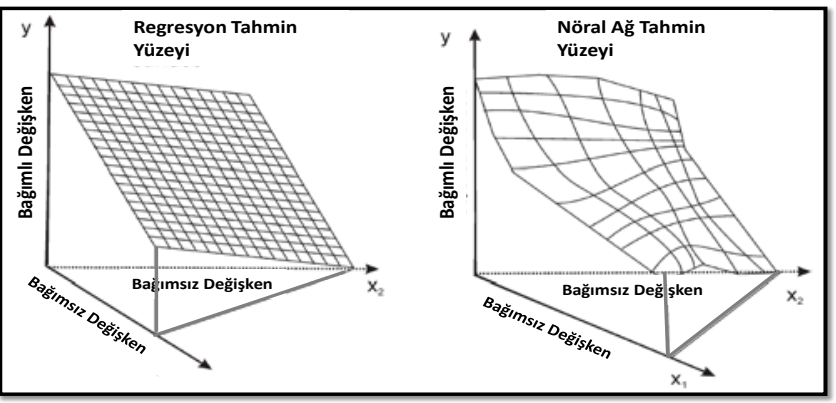

Şekil 5. Regresyon modelleri ve YSA tahmin yüzeylerinin karşılaştırılması (Lloyd, 1997).

Figure 5. Comparison of regression models and ANN prediction surfaces

YSA yönteminin kullanım kısıtlığı "kara-kutu" model olmasıdır. Bu nedenle çalışan bir YSA ağındaki ağırlıkları yorumlamak oldukça güçtür. Yine de farklı girdilerin sayısal analizi, özelliklerin önemini anlamaya yardımcı olmaktadır. Çok kolay bir şekilde yorumlanabilen karar ağacı (decision tree) ile kıyaslandığında, YSA'nın en önemli avantajlarından biri, girdi değişkenleri arasındaki bilinmeyen etkileşimleri, bu etkileşimler arasındaki ilişkileri ve çıktı paternini modelleyebilme yeteneğidir (Pyle, 1999).

Kent arazi dinamikleri üzerine YSA uygulamaları genel olarak iki yaklaşımı içermektedir. Bu yaklaşımlardan birincisi, YSA yönteminin arazi örtüsü sınıflandırmalarında kullanılmasıdır. Pijanowski vd. (2002), yaptıkları çalışmada YSA yöntemini kullanarak bir bölgedeki gelişim paternini öğrenmişler ve arazi transformasyon modeli tahmin edebilme kapasitesini test etmişlerdir. Pijanowski vd. (2005) Amerika Birleşik Devletleri'ndeki iki şehir için bir YSA modeli oluşturmuş ve iki metropoliten bölge arasında modellerin transfer edilip edilemeyeceğini test etmişlerdir. Zhang ve Yu (2006) arazi örtüsü paterni üzerine CBS temelli analizleri YSA ile entegre etmiş ve kantitatif olarak kentleşme paternini karakterize etmişlerdir. YSA kullanımında ikinci yaklaşım ise, kentsel büyüme modelleri için uygun parametre belirlemeye yöneliktir. Li ve Yeh $(2001,2002)$ Güney Çin'deki kent kümelerinin arazi kullanım değişimi üzerine bir model oluşturmuş ve YSA yönteminin öğrendiği parametre değerlerini $\mathrm{HO}$ modeli içine entegre etmişlerdir. Daha sonra çoklu bölgesel arazi kullanımları ve alternatif gelişim senaryoları üzerine simülasyon oluşturan modelleri yeni duruma göre tekrar uyarlamışlardır (Yeh ve Li, 2003).

\section{SONUÇ}

Kent gelişimini ortaya koymak için hazırlanan simülasyon modellerinde uygulanan matematiksel eşitlikler, kentlerin gelişiminde çok sayıda değişken bulunması ve bu değişkenlerin birbirini doğrusal olarak etkilememesi nedeniyle, sistemi açıklamada yetersiz kalmaktadır. Zamansal ve mekânsal verilerin normal dağılım göstermemesi, bağımlı ve bağımsız değişkenlerin hata yapısı, model doğrusallığı gibi temel varsayımların ihmal edildiği klasik kantitatif yöntemler, karmaşık mekânsal problemleri çözemez. Bu nedenle daha gerçekçi ampirik yöntemlerle elde edilen kentsel büyüme modellerine ihtiyaç duyulmuştur. Bu modellerden biri olan ve $\mathrm{HO}$ geçiş kurallarının kalibre edilmesinde etkili bir araç olarak kullanılan YSA modeli ile yapılan çalışmaların sayısı giderek artmaktadır.

YSA modelinin ATM ve HO gibi yöntemlere göre iki önemli avantajı vardır. Bunlardan birincisi, gelişim alternatifleri oluşturulurken parametre değerlerindeki belirsizliği minimum seviyeye getirebilmesi ve bu değerlerin nasıl belirleneceğini göstermesidir. İkincisi bu modelin, alternatif kent büyümesini simüle edebilmesidir. Bu nedenle YSA arazi kullanım değişimi olasılıklarının hesaplanmasında alternatif bir yöntem olarak düşünülmektedir. Sonuç olarak, YSA sisteminin mekânsal verinin belirsizliğini iyi bir şekilde analiz edebilme kabiliyetinden dolayı, geleneksel istatistik yöntemlere göre daha üstün bir performansa sahip olduğu söylenebilir.

\section{KAYNAKLAR}

Alig, R.J. and Healy, R.G. (1987) "Urban and Built-up Land Area Changes in the US: An Empirical Investigation of Determinants", Land Economics 63(3), 215-226.

Allen, P.M. and Sanglier, M. (1981) "Urban Evolution, Self Organization and Decision Making", Environment and Planning A 13(2), 167-183.

Batty, M. and Xie, Y. (1994) "From Cells to Cities", Environment and Planning B: Planning and Design 21, 531-548.

Batty, M., Xie, Y.C. and Sun, Z.L. (1999) "Modeling Urban Dynamics through GIS-Based Cellular Automata", Computer, Environment and Urban Systems 23, 205233.

Batty, M. (2007) Model Cities, Centre for Advanced Spatial Analysis Working Paper Series, Paper 113, Şubat 2007. (http://www.casa.ucl.ac.uk/working_papers.htm, 16.07.2010).

Bishop, C.M. (1995) Neural Networks for Pattern Recognition, Clarendon Press, Oxford.

Benenson, I. and Torrens, P.M. (2004) Geosisimulation: Automata-Based Modeling of Urban Phenomena, John Wiley, London.

Berger, T. (2001) Agent-Based Spatial Models Applied to Agriculture: A Simulation Tool for Technology Diffision, Resource Use Changes and Policy Analysis", Agriculture Economics 25, 245-260.

Brown, G. and Robinson, D.T. (2006) "Effects of Heterogeneity in Preferences on an Agent-Based 
Model of Urban Sprawl", Ecology and Society 11(1), 46.

Cheng, J. and Masser, I. (2003) "Urban Growth Modeling: A Case Study of Wuhan City, PR China", Landscape and Urban Planning 62, 199-217.

Clarke, K.C., Gaydos, L. and Hoppen, S. (1997) "A selfModifying Cellular Automaton Model of Historical Urbanization in the San Francisco Bay area", Environment and Planning B: Planning and Design 24, 247-261.

Clarke, K.C. and Gaydos, L.J. (1998) "Loose-Coupling a Cellular Automata Model and GIS: Long-Term Urban Growth Prediction for San Francisco and Washington/Baltimore", International Journal of Geographical Information Science 12(7), 699-714.

Couclelis, H. (1997) "From Cellular Automata to Urban Models: New Principles for Model Development and Implementation", Environment and Planning B: Planning and Design 24, 165-174.

Fischer, M.M. and Gopal, S. (1994) "Artificial Neural Networks: A New Approach to Modelling Interregional Telecommunication Flows", Journal of Regional Science 34, 503-527.

Guan, Q., Wang, L. and Clarke, K.C. (2005) "An ArtificialNeural-Network-Based, Constrained CA Model for Simulating Urban Growth", Cartography and Geographic Information Science 32(4), 369-380.

Happe, K. (2004) Agriculture Policies and Form Structures Aged Based Modelling and Application to EU-Policy Reform, Institute of Agricultural Development in Central and Eastern Europe (IAMO), 30.

He, C., Okada, N., Zhang, Q., Shi, P. and Li, J. (2008) "Modelling Dynamic Urban Expension Processes Incorporating a Potential Model with Cellular Automata", Landscape and Urban Planning 86, 79-91.

Jacquin, A., Misakova, L. and Gay, M. (2008) "Ahybrid Object-Based Classification Approach for Mapping Urban Sprawl in Periurban Environment", Landscape and Urban Planning 84(2), 152-165.

Krenker, A., Bešter, J. and Kos, A. (2011) "Introduction to the Artificial Neural Networks", İçinde: Suzuki, K. (Ed). Artificial Neural Networks-Methodological Advances and Biomedical Applications. InTech, Croatia.

Lansing, J.S. and Kremer, J.N. (1993) “Emergent Properties of Balinese Water Temple Networks: Coadaptation on a Rugged Fitness Landscape", American Antropologist 95(1), 97-114.

Lee, J., Klosterman, R.E., Salling, M. and Kulikowski, T.D. (1999) Development of a Community-Accessible Urban Sprawl Impact Assessment System in Northeast Ohio 15-County Region for the Empact Project, Phase One report, Literature Review for Urban Growth Modeling and Environmental Impact Analysis [online]. Washington, DC, US Environmental Protection Agency, Grant No. 985989-01-0. Available from: $\mathrm{ftp}: / /$ gis.geog.kent.edu/EMPACT/ review.pdf/ [Accessed 26 December 2011].
Li, X. and Yeh, A.G.O. (2000) "Modelling Sustainable Urban Development by the Integration of Constrained Cellular Automata and GIS", International Journal of Geographical Information Science 14(2), 131-152.

Li, X. and Yeh, A.G.O. (2001) "Calibration of Cellular Automata by Using Neural Networks for the Simulation of Complex Urban Systems", Environment and Planning A 33, 1445-1462.

Li, X. and Yeh, A.G. (2002) "Neural-Network-Based Cellular Automata for Simulating Multiple Land Use Changes Using GIS", International Journal of Geographical Information Science 16, 323-343.

Ligmann-Zielinska, A. and Jankowski, P. (2007) “AgedBased Models as Laboratories for Spatially Explicit Planning Policies", Environment and Planning B: Planning and Design 34, 316-335.

Ligtenberg, A., Wachowicz, M., Bregt, A.K., Beulens, A. and Kettenis, D.L. (2004) "A Design and Application of a Multi-Agent System for Simulation of Multi-Actor Spatial Planning", Journal of Environmental Managament 72, 43-55.

Lloyd, R. (1997) Spatial Cognition: Geographic Environments, Kluwer Academic Publishers, Dordrecht, The Netherlands.

Lopez, E., Bocco, G., Mendoza, M. and Duhau, E. (2001) "Predicting Land Cover and Land Use Change in the Urban Fringe: A Case in Morelia City Mexico", Landscape and Urban Planning 55(4), 271-285.

Maithani, S. (2009) "A Neural Network Based Urban Growth Model of an Indian City", Journal of the Indian Society of Remote Sensing 37, 363-376.

Matthews, R.B., Gilbert, N.G., Roach, A., Polhill, J.G., Gotts, N.M. (2007) "Aged-Based Land-Use Models: A Review of Applications, Landscape Ecology 22, 1447-1459.

Openshaw, S. (1993) “Modelling Spatial Interaction Using a Neural Net", İçinde, GIS, Spatial Modelling and Policy, Springer, Berlin, Germany, 147-164.

Pijanowski, B.C., Brown, D.G., Shellito, B.A. and Manik, G.A. (2002) "Using Neural Networks and GIS to Forecast Land Use Changes: A Land Transformation Model", Computers, Environment and Urban Systems 26(6), 553-575.

Pijanowski, B.C., Pithadia, S., Shellito, B.A. and Alexandridis, K. (2005) "Calibrating a Neural NetworkBased Urban Change Model for Two Metropolitan Areas of the Upper Midwest of the United States", International Journal of Geographical Information Science 19, 197-215.

Pyle, D. (1999) Preparation for Data Mining, Morgan Kaufmann Publishers, San Francisco, CA.

Tobler, W.R. (1970) "Computer Movie Simulating Urban Growth in the Detroit Region", Economic Geography 46, 234-240.

Ward, D.P., Murray, A.T. and Phinn, S.R. (2000) "A Stochastically Constrained Cellular Model of Urban Growth", Computers, Environment and Urban Systems 24, 539-558. 
White, R. and Engelen, G. (1993) "Cellular Automata and Fractal Urban Form: A Cellular Modelling Approach to the Evolution of Urban Land-Use Patterns", Environment and Planning A 25, 1175-1199.

White, R. and Engelen, G. (1994) "Cellular Dynamics and GIS: Modelling Spatial Complexity", Geographical Systems 1, 237-253.

White, R., Engelen, G. and Uijee, I. (1997) "The Use of Constrained Cellular Automata for High-Resolution Modelling of Urban Land-Use Dynamics", Environment and Planning B: Planning and Design 24, 323-343.

Wolfram, S. (1984) "Cellular Automata as Models of Complexity", Nature 311, 419-424.

Wolfram, S. (1988) Complex Systems Theory, Emerging Syntheses in Science: Proceedings of the Foundaing Workshops of the santa Fe Institute, Adisson-Wesley, Reading, MA.

Wu, F. and Webster, C.J. (1998) "Simulation of Land Development through the Integration of Cellular Automata and Multicriteria Evaluation", Environment and Planning B: Planning and Design 25, 103-126.

$\mathrm{Wu}$, F. and Yeh, A.G.O. (1997) "Changing Spatial Distribution and Determinants of Land Development in Chinese Cities in the Transition from a Centrally Planned Economy to a Socialist Market Economy: A Case Study of Guangzhou", Urban Studies 34(11), 1851-1879.

$\mathrm{Wu}$, F. (1998) "An Experiment on the Generic Polycentricity of Urban Growth in a Cellular Automatic City", Environment and Planning B: Planning and Design 25, 103-126.

Wu, F. (2005) Introduction-Urban Simulation. İçinde: Atkinson, P.M., Foody, Giles, M., Darby, Steve, E., Wu, F. (Eds). GeoDynamics. CRC Press, Boca Raton, FL.

Yeh, A.G.O. and Li, X. (2001) "A Constrained CA Model for the Simulation and Planning of Suitainable Urban Forms Using GIS", Environment and Planning B: Planning and Design 28, 733-753.

Yeh, A.G. and Li, X. (2003) "Simulation of Development Alternatives Using Neural Networks, Cellular Automata, and GIS for Urban Planning", Photogrammetric Engineering and Remote Sensing 69, 1043-1052.

Zhang, L. and Yu, Z. (2006) “An Artificial Neural Network Model of the Landscape Pattern in Shanghai Metropolitan Region, China", Frontiers of Biology in China 1(4), 463-469. 